Gut, 1975, 16, 800-807

\title{
Serum transaminase levels after experimental paracetamol-induced hepatic necrosis
}

\author{
M. F. DIXON, M. J. FULKER, B. E. WALKER, J. KELLEHER, AND \\ M. S. LOSOWSKY \\ From the Departments of Pathology, Experimental Pathology and Cancer Research, and Medicine, \\ University of Leeds
}

SUMMARY The relationship between serum transaminase levels and the extent of paracetamolinduced liver necrosis has been investigated in the rat. Three methods of histological quantitation were used to assess the degree of necrosis - arbitrary grading, point counting, and the image-analysis computer. Highly significant correlations were obtained between the three methods and all were found to be reproducible. A close correlation was found between the extent of hepatic necrosis and the serum ASAT and ALAT 24 hours after a large dose $(4 \mathrm{~g} / \mathrm{kg})$ of paracetamol. Likewise, the mean grade of necrosis correlated reasonably well with the serum enzyme levels in the recovery phase at 36 and 72 hours, although the transaminase level for a given degree of necrosis was considerably lower at 72 hours than at 24 hours. These findings suggest that serum transaminase levels give a reliable indication of the severity of hepatic necrosis if the time of ingestion of the paracetamol is known and taken into account.

Elevation of serum transaminase levels has invariably been used as an index of liver damage in detecting hepatic necrosis complicating cases of self-poisoning with paracetamol. Striking increases in these enzymes have been found in a few such patients, who, however, judging by other liver function tests and their clinical state, do not appear to have correspondingly severe liver damage (Prescott, Wright, Roscoe, and Brown, 1971; personal observations). The relation between peak serum enzyme values and the subsequent development of hepatic failure has not been studied in these patients; other parameters such as the plasma paracetamol half-life (Prescott et al, 1971) and the increase in serum bilirubin and prothrombin ratio (Clark, Thompson, Borirakchanyavat, Widdop, Davidson, Goulding, and Williams, 1973) have been proposed as better prognostic indices. The absence of information on the relation between serum transaminase levels and the extent of paracetamolinduced liver injury led us to investigate the problem, using the rat as an experimental model.

Previous experience with paracetamol overdosage in the rat indicated that significant increases in serum transaminase do not occur before the appearance of frank necrosis which is first seen at 12 hours

Received for publication 9 July 1975.
(Dixon, Dixon, Aparicio, and Loney, 1975) and that maximum elevation usually occurs 24 hours after administration (Walker, Kelleher, Dixon, and Losowsky, 1973). Thus serum transaminase levels were correlated with histological necrosis from 24 hours after a large dose of paracetamol until well into the recovery phase.

\section{Materials and Methods}

In the first experiment rats were killed 24 hours after a large hepatotoxic dose of paracetamol, and serum transaminase levels at the time of death were correlated with the degree of hepatic necrosis. Two further experiments were performed in which groups of rats were killed at 36 hours and 72 hours after paracetamol to study the relation in the recovery phase. The experiments also provided an opportunity to evaluate three methods of quantitation of liver necrosis, namely, arbitrary grading, point counting, and the image-analysis computer.

Female Tuck-Wistar rats weighing approximately $200 \mathrm{~g}$ were used throughout. Paracetamol BPC was administered by stomach tube without anaesthesia in a dose of $4 \mathrm{~g} / \mathrm{kg}$ body weight as a suspension $(300 \mathrm{mg} / \mathrm{ml})$ in $0.2 \%$ tragacanth and water. The animals were fasted for 16 hours before administration. The 20 rats in the main group were killed 24 
hours after paracetamol, and groups of 6 and 10 rats were killed at 36 and 72 hours respectively.

Samples of blood for transaminase estimations were taken by cardiac puncture under light ether anaesthesia immediately before the animals were killed. Serum aspartate aminotransferase (ASAT, formerly SGOT) and alanine aminotransferase (ALAT, formerly SGPT) were determined by a modification (Henry, Chiamori, Golub, and Berkman, 1960) of the methods of Karmen (1955) and Wroblewski and La Due (1956) respectively, as described by Walker, Kelleher, Dixon, and Losowsky (1974).

The animals were killed by cervical dislocation. The livers were immediately removed and a series of cuts was made into the lobes to ensure adequate penetration of the fixative $(10 \%$ buffered formolcalcium) in which they were immersed. After fixation for 48 hours the lobes were separated and cut into thin slices $(2-3 \mathrm{~mm})$ along their long axes and alternate slices were taken for histology. This provided eight to 16 (mean 10.1) pieces of liver ('blocks') for each animal. The blocks were identified separately. A further 24 hours in fixative was followed by paraffin embedding and $5 \mu \mathrm{m}$ sections were cut and stained with Harris's haematoxylin and eosin (HE) and with Pyronin Y (see below).

The extent of necrosis in the HE section of each block was graded (by MFD) on a scale 1-5 which attempted to represent four equal increments between scattered small centrilobular foci of necrosis (grade 1) and complete destruction of the parenchyma (grade 5). Often there was considerable variability in the extent of necrosis within the same block and a compromise grade had to be allocated. The mean of the grades for individual blocks gave a final grade of necrosis for each animal. In order to assess reproducibility of this method, a second grading was performed 'blind' several weeks after the first. The accuracy of subjective grading was examined by correlating the theoretical percentage necrosis equivalent to the mean grade, on the basis of $1=20 \%, 2=40 \%$, etc, with the percentage necrosis as determined by point counting.

Point counting was performed on the sections from the 24-hour group using a 25-point random array eyepiece graticule. Twenty non-overlapping consecutive fields were counted with a $\times 10$ objective and $a \times 10$ eyepiece giving a total of 500 points for each block. The number of points falling on viable hepatocytes, necrotic hepatocytes, and on portal tracts, central veins or sinusoids was recorded. The point counts for these various components are directly proportional to the volume that each component occupies in the liver, so that the proportion of the total parenchyma occupied by necrotic cells can be calculated for each block. The mean of the results for individual blocks gave the percentage necrosis for each animal.

The theoretical accuracy of point counting can be estimated using the Gauss equation for the standard error $\mathbf{S}_{\mathbf{x}}$ (expressed as a percentage of the component being measured) which is given by the formula

$$
S_{\bar{x}}=67.45 \sqrt{\frac{100-c \%}{n c}}
$$

where $\mathrm{n}$ is the number of observations made for the presence or absence of a component type that occupies c\% of the whole area (Curtis, 1960). On the basis of 500 observations per block, for levels of necrosis greater than $25 \%$ the standard error will be less than $5 \%$, and taken over the average of 10.5 blocks for each animal in the 24-hour group even at low levels of necrosis the theoretical accuracy of the method will be acceptable, eg, for $5 \%$ necrosis $\mathrm{S}_{\overline{\mathrm{x}}}=4 \%$.

The reproducibility of the method was tested by counting 'blind' the HE-stained sections from one of the animals a second time.

Finally, 10 of the 24-hour livers, having over $25 \%$ necrosis by point counting, were examined on the Quantimet image analyser (720D, Image Analysing Computers, Ltd). The computer utilizes a digitally controlled plumbicon scanner to provide a videoscreen image of the histological section viewed through an optical microscope. By setting three grey-level thresholds, various components of the image can be identified and quantified separately. The instrument used was fitted with a shading corrector to compensate for the inevitable slight unevenness of the microscope illumination and sensitivity of the scanner. This technique has not been previously employed to quantitate liver necrosis and it was first necessary to choose a staining technique which was susceptible to analysis in monochrome. We have utilized the loss of pyroninophilia in degenerating hepatocytes to distinguish viable cells (bright crimson) from necrotic cells (pale pink) after staining with $1 \%$ Pyronin $\mathrm{Y}$ in $0.2 \mathrm{M}$ Walpole's acetate buffer ( $\mathrm{pH} 4 \cdot 2$ ) for 10 minutes. The relationship between the degree of necrosis as demonstrated by the Pyronin Y stain and by HE was checked by point counting the Pyronin sections. The sections were viewed through a green filter (Wratten no. 58) to improve the contrast and facilitate detection of the necrotic areas and 'clear' areas separately. Using the $\times 5$ objective with the full frame equivalent to a specimen area of $2 \cdot 1$ $\mathrm{mm}^{2}$, three areas were measured for each field corresponding theoretically to: $a=$ 'clear' areas, ie, portal tracts, central veins, sinusoids, and areas not 


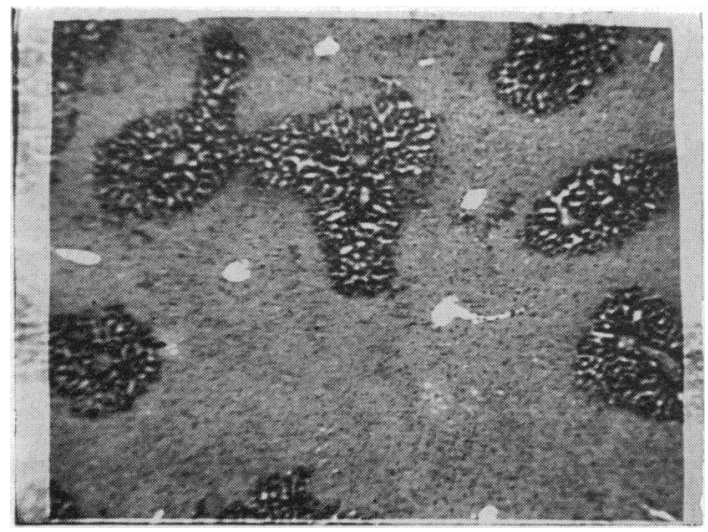

Fig 1

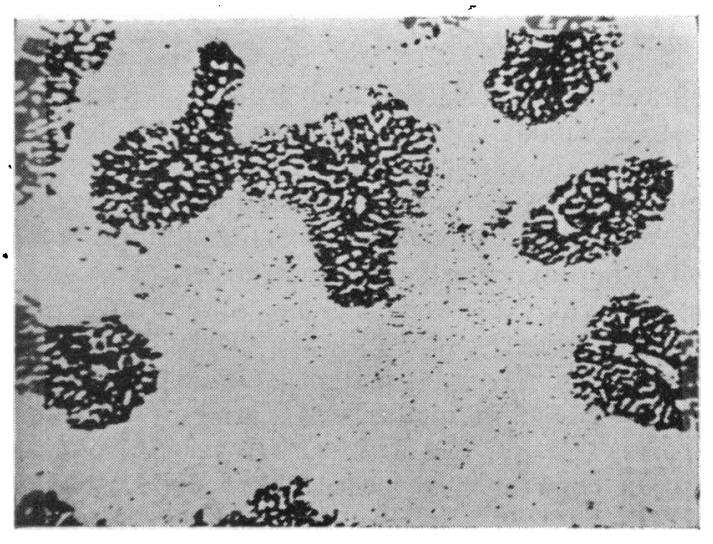

Fig 2

Fig 1 Video-screen image of Pyronin Y-stained section of liver showing the first threshold setting which detects central veins, vessels in portal tracts, and sinusoids. The area detected (a) is measured in picture points and displayed above the image.

Fig 2 Second threshold setting detects area a together with the necrotic tissue (= area b). It is evident that this setting, in addition to detecting necrotic tissue, is detecting more sinusoidal spaces than the first setting and failing to detect dense nuclear material in the necrotic zones. The latter contributes to the area c measured by the third threshold setting.

occupied by tissue such as cracks in the section, or around the margins of the block (fig 1$) ; b=$ necrotic parenchyma $+a$ (fig 2); $c=$ viable parenchyma + $b$, ie, everything but occasional small fragments of densely stained debris or other foreign material.

The three thresholds were set for each field and the areas $a, b$ and $c$ measured in picture points by the programmer and recorded on eight-track tape. The settings were carried out without any knowledge of the point counting results (MJF). The microscope was fitted with a scanning stage, set in this instance to scan the specimen on a square raster in steps of $2.5 \mathrm{~mm}$, corresponding approximately to almost complete coverage of the section with non-overlapping fields as viewed through a $\times 5$ objective. Empty fields or fields where the tissue occupied less than half of the displayed area were not measured. In this way the number of fields measured for each block was approximately proportional to the section area.

\section{For each frame}

The area of necrotic tissue $=b-a$

The total area of parenchyma $=c-a$

Therefore, the percentage necrosis $(\mathrm{N})=$

$$
\frac{b-a}{c-a} \times 100
$$

The picture-point areas of each component were fed into an ICL 1906A computer which calculated the percentage necrosis for each field, and the mean percentage necrosis of all the fields scanned for each animal.

\section{Results}

\section{ASSESSMENT OF NECROSIS}

The degrees of hepatic necrosis as assessed by grading and point counting at $\mathbf{2 4}$ hours are given in table $I$. It can be seen that the grades of necrosis given on two separate occasions by the same observer show only minor differences and are clearly reproducible (Pearson correlation coefficient $r=0.98$ significance, $P<0.001$ for the mean grades of runs 1 and 2).

The reproducibility of point counting the HE sections from one animal (18) is illustrated in table II. Whilst the mean percentage necrosis as determined on two occasions is almost identical, there is in two out of the 10 blocks considerable variation between the two determinations. However, the overall correlation between run 1 and run 2 was very close $(r=0.86, P<0.001)$. Table II also illustrates the marked variation in the degree of necrosis from block to block, a feature seen throughout the material, and underlines the need for multiple samples. Had only two blocks been taken from this liver, for example, they could have given results ranging from $6.1 \%$ to $51 \cdot 3 \%$, compared with the overall mean of $25.0 \%$. Table II also shows the 


\begin{tabular}{|c|c|c|c|c|c|}
\hline \multirow[t]{2}{*}{ Rat } & \multicolumn{2}{|c|}{ Mean Grade of Necrosis $\pm S E^{1}$} & \multirow{2}{*}{$\begin{array}{l}\text { Mean Percentage Necrosis } \\
\text { (Point Counting) } \pm S E\end{array}$} & \multicolumn{2}{|c|}{ Serum Transaminase Levels (iu/D) } \\
\hline & Run 1 & Run 2 & & $A S A T$ & $A L A T$ \\
\hline $\begin{array}{r}1 \\
2 \\
3 \\
4 \\
5 \\
6 \\
7 \\
8 \\
9 \\
9 \\
10 \\
11 \\
12 \\
13 \\
14 \\
15 \\
16 \\
17 \\
18 \\
19 \\
20\end{array}$ & $\begin{array}{l}3.0 \pm 0.26 \\
2.8 \pm 0.29 \\
3.2 \pm 0.3 \\
0 \\
2.2 \pm 0.3 \\
3.3 \pm 0.28 \\
2.3 \pm 0.15 \\
4.5 \pm 0.25 \\
1.7 \pm 0.37 \\
2.2 \pm 0.2 \\
3.5 \pm 0.15 \\
2.6 \pm 0.15 \\
1.1 \pm 0.23 \\
1.0 \pm 0.13 \\
2.2 \pm 0.25 \\
0.9 \pm 0.14 \\
2.9 \pm 0.09 \\
2.5 \pm 0.31 \\
0 \\
2.9 \pm 0.1\end{array}$ & $\begin{array}{l}2.5 \pm 0.38 \\
2.2 \pm 0.42 \\
3.1 \pm 0.29 \\
0 \\
2.1 \pm 0.29 \\
3.0 \pm 0.24 \\
2.2 \pm 0.2 \\
4.4 \pm 0.24 \\
1.7 \pm 0.33 \\
2.5 \pm 0.17 \\
3.0 \pm 0 \\
2.5 \pm 0.16 \\
1.0 \pm 0.25 \\
1.0 \pm 0.13 \\
2.0 \pm 0.26 \\
0.7 \pm 0.18 \\
2.6 \pm 0.15 \\
1.9 \pm 0.28 \\
0 \pm 0.13 \\
2.8 \pm 0.13\end{array}$ & $\begin{array}{r}40.4 \pm 8.2 \\
29.0 \pm 5.0 \\
53.6 \pm 6.1 \\
0 \\
28.9 \pm 6.3 \\
51.6 \pm 4.0 \\
28.1 \pm 3.2 \\
67.0 \pm 5.6 \\
16.6 \pm 6.5 \\
25.8 \pm 2.8 \\
46.0 \pm 2.5 \\
28.4 \pm 2.4 \\
12.2 \pm 5.2 \\
4.8 \pm 1.3 \\
32.0 \pm 4.0 \\
0.2 \pm 0.1 \\
31.4 \pm 3.0 \\
25.0 \pm 5.7 \\
0 \\
36.4 \pm 2.1\end{array}$ & $\begin{array}{r}3520 \\
3410 \\
11730 \\
746 \\
12800 \\
11090 \\
4693 \\
11300 \\
2069 \\
1920 \\
7680 \\
3093 \\
2026 \\
261 \\
9490 \\
300 \\
3330 \\
1620 \\
464 \\
7250\end{array}$ & $\begin{array}{r}1056 \\
1717 \\
3040 \\
85 \\
2293 \\
3157 \\
1578 \\
2810 \\
661 \\
853 \\
1920 \\
1269 \\
1120 \\
58 \\
1344 \\
69 \\
1700 \\
500 \\
148 \\
3500 \\
\end{array}$ \\
\hline
\end{tabular}

Table I Mean grade of hepatic necrosis, mean percentage necrosis as assessed by point counting, and serum transaminase levels in rats killed 24 hours after paracetamol

${ }^{1}$ Correlation coefficients and significance:

Run 1 v run 2: $\mathrm{r}=0.98, \mathrm{P}<0.001$; run $1 \mathrm{v}$ ASAT: $\mathrm{r}=0.67, \mathrm{P}<0.001$; run 1 v ALAT: $\mathrm{r}=0.77$, $\mathrm{P}<0.001$

Run 1 v point count $(\%): r=0.96, \mathrm{P}<0.001 ;$ run 2 v ASAT: $r=0.70, \mathrm{P}<0.001 ;$ run 2 v ALAT: $r=0.79, \mathrm{P}<0.001$

Run 2 v point count $(\%): r=0.96, P<0.001 ; \%$ necrosis $v$ ASAT: $r=0.80, P<0.001 ; \%$ necrosis $v$ ALAT: $r=0.84, P<0.001$

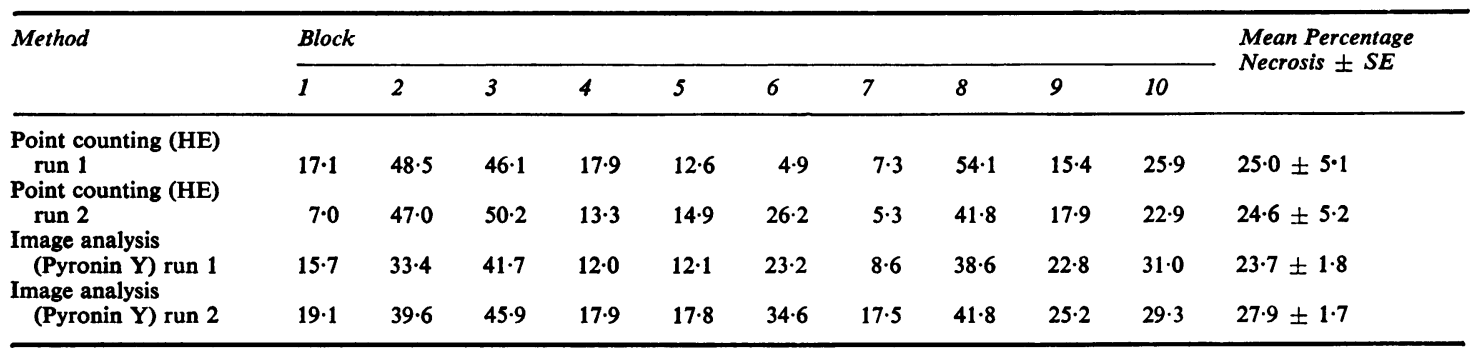

Table II Reproducibility of point counting and image analysis in rat 18

image-analysis results for this animal determined on two separate occasions. There is a very close correlation between the two runs $(r=0.952$, $\mathrm{P}<$ 0.001 ), which demonstrates the good reproducibility of this method.

In order to test the validity of arbitrary grading as a measure of necrosis, the mean grades (run 1) were correlated with the corresponding percentage necrosis obtained by point counting the HE sections. The correlation coefficient of 0.96 is highly significant $(\mathrm{P}<0.001)$.

The Quantimet image analyser was used to measure the percentage necrosis in sections of 10 livers stained by the Pyronin Y method. It was first necessary to establish that this stain gave an accurate representation of hepatic necrosis as compared with the orthodox HE method. The results of point counting the two stains and of the image analysis are given in table III. There was a highly significant correlation between the point counting and imageanalysis results which, as would be expected, was marginally better for Pyronin Y than for HE ( $r=$ 0.92 and 0.88 respectively; $P<0.001$ for each).

Despite the good correlation and near equivalence of the final results the image-analysis method had some shortcomings. The threshold for area $a$ (portal tracts, central veins and sinusoids) could not always be set to detect all these components without including some of the necrotic tissue. Thus some areas which theoretically ought to contribute to $a$ would be excluded and only contribute to $b$ and $c$. There was also grey-level overlap across the second threshold so that pyknotic nuclei in necrotic areas contributed to $c$ only, instead of to $b$ and $c$. The 


\begin{tabular}{|c|c|c|c|}
\hline \multirow[t]{3}{*}{ Rat } & \multicolumn{3}{|c|}{ Percentage Necrosis ( $\pm S E)$ as Assessed by } \\
\hline & \multicolumn{2}{|c|}{ Point Counting } & \multirow{2}{*}{$\begin{array}{l}\text { Image Analysis } \\
\text { (Pyronin Y) }\end{array}$} \\
\hline & $H E$ & Pyronin $Y$ & \\
\hline 1 & $40 \cdot 4 \pm 8 \cdot 2$ & $38.4 \pm 7.8$ & $37 \cdot 3 \pm 2 \cdot 9$ \\
\hline 2 & $29.0 \pm 5.0$ & $27 \cdot 6 \pm 7 \cdot 4$ & $26.0 \pm 1.8$ \\
\hline 3 & $53.6 \pm 6.1$ & $43 \cdot 3 \pm 5 \cdot 2$ & $34.8 \pm 2 \cdot 1$ \\
\hline 5 & $28.9 \pm 6.3$ & $32.0 \pm 5.9$ & $31.2 \pm 2.6$ \\
\hline 6 & $51.6 \pm 4.0$ & $44.7 \pm 5.6$ & $40 \cdot 3 \pm 2 \cdot 2$ \\
\hline 7 & $28 \cdot 1 \pm 3 \cdot 2$ & $24.9 \pm 3.0$ & $32.5 \pm 1.4$ \\
\hline 8 & $67.0 \pm 5.6$ & $60.5 \pm 6.7$ & $57.2 \pm 2.4$ \\
\hline 10 & $25.8 \pm 2.8$ & $26.6 \pm 3.9$ & $17.0 \pm 1.6$ \\
\hline 15 & $32.0 \pm 4.0$ & $29 \cdot 1 \pm 3.8$ & $32.5 \pm 1.9$ \\
\hline 18 & $25.0 \pm 5.7$ & $22 \cdot 3 \pm 4 \cdot 7$ & $23.7 \pm 1.8$ \\
\hline
\end{tabular}

Table III Comparison of point-counting and imageanalysis methods

Point counting (HE) v point counting (Pyronin): $r=0.976, P<0.001$ Point counting (HE) v image analysis (Pyronin): $\mathrm{r}=0.88, \mathrm{P}<0.001$ Point counting (Pyronin) vimage analysis (Pyronin): $r=0.92, P<0.001$ Percentage necrosis (image analysis) v ASAT: $r=0.622, \mathrm{P}<0.05$ Percentage necrosis (image analysis) v ALAT: $r=0.657, \mathrm{P}<0.05$

effect of these detection errors is that first incomplete detection of component $a$ increases both $b-a$ and $c-a$; but since $c-a>b-a$, the percentage necrosis (N) obtained from $\frac{b-a}{c-a} \times 100$ will be too high. Secondly, incomplete detection of nuclear material in $b$ will result in values for $b$ and $b-a$ which are too low, giving a low value for $\mathrm{N}$. Thus, the two most important shortcomings of the detection procedure tend to balance each other out.

\section{RELATION BETWEEN NECROSIS AND SERUM} ENZYMES

The serum transaminases at 24 hours in the first experiment are shown in table I and correlated with the grade of necrosis and percentage necrosis as determined by point counting. Although for both enzymes there are extreme variations in the response of individual animals, the enzyme levels nevertheless closely reflected the subsequently determined severity of necrosis. The correlation between ALAT or ASAT was closer when compared with percentage necrosis as determined by point counting than with grade of necrosis but all correlations (table I) were highly significant $(P<0.001)$. ALAT gave a better correlation than ASAT with both methods of assessing necrosis but the advantages of using one or other of the two enzymes were only minimal. As expected the serum enzyme values at 24 hours also correlated well with the image-analysis method of assessing necrosis (tables I and III).

In the recovery phase the correlation between serum enzymes and severity of necrosis is less close. The results at 36 and 72 hours are shown in table IV. The correlation between the mean grade of necrosis and serum ASAT at both times reached statistical significance at the $5 \%$ level, but with ALAT just failed to reach significance at this level. Nevertheless these results indicate that even in the recovery phase the serum enzyme levels can be used with reasonable confidence to assess the degree of necrosis that has taken place.

\section{Discussion}

Serum transaminases were first used as an index of hepatocellular injury by Molander, Wroblewski, and La Due (1955) in a study of carbon tetrachlorideinduced necrosis in rats. Since then there have been several studies of transaminase levels after various types of liver injury. Friend, Wroblewski, and La Due (1955) examined SGOT activity in mice with viral hepatitis, and further studies have been carried out using carbon tetrachloride alone (Block and Cornish, 1958; Richarz and Schoetensack, 1959; Wirtschafter and Tsujimura, 1961; Fox, Dinman, and Fajola, 1962; Gabrieli and Orfanos, 1968;

\begin{tabular}{|c|c|c|c|c|c|c|c|}
\hline \multirow[t]{2}{*}{ Rat } & \multicolumn{3}{|l|}{36 Hours } & \multirow[t]{2}{*}{ Rat } & \multicolumn{3}{|l|}{72 Hours } \\
\hline & Mean Grade $\pm S E^{1}$ & $A S A T(i u / l)$ & $A L A T(i u / l)$ & & Mean Grade $\pm S E$ & $A S A T(i u / l)$ & $A L A T(i u / l)$ \\
\hline
\end{tabular}

Table IV Mean grades of necrosis and transaminase levels at 36 and 72 hours after paracetamol

'Correlation coefficients and significance: Mean grade $36 \mathrm{hr}$ v ASAT: $\mathrm{r}=0.823, \mathrm{P}<0.05$

Mean grade $36 \mathrm{hr}$ v ALAT: $\mathrm{r}=0.611, \mathrm{P}<0.1,>0.05$

Mean grade $72 \mathrm{hr}$ v ASAT: $\mathrm{r}=0.640, \mathrm{p}<0.05$

Mean grade $72 \mathrm{hr}$ v ALAT: $\mathrm{r}=0.575, \mathrm{p}<0.1,>0.05$ 
Magos, Butler, White, and Green, 1974), or, together with other hepatotoxins such as thioacetamide (Grice, Barth, Cornish, Foster, and Gray, 1971), sodium selenate (Cutler, 1974), various chlorinated hydrocarbons (Klaassen and Plaa, 1967) and a wide range of toxic compounds (Balazs, Murray, McLaughlan, and Grice, 1961). In addition Strubelt, Breining, and Praël (1973) have studied serum transaminase changes after mechanical injury to the liver.

These experiments have usually included histological examination of the liver but in the majority a purely descriptive morphological analysis has been compared with the enzyme changes. In five studies the histological changes have been graded (Balazs et al, 1961; Grice et al, 1971; Strubelt et al, 1973; Cutler, 1974; Magos et al, 1974) and, in general, the serum transaminase levels reflected the presence and severity of hepatic necrosis. Zelman, Wang, and Appelhanz (1959) compared the grade of hepatic necrosis in 143 human aspiration biopsies with simultaneous determinations of SGOT and SGPT. They found an excellent correspondence between the extent of necrosis of liver cells and the rise in serum activity of either enzyme.

Previous experience of grading paracetamolinduced hepatic necrosis (Nimmo, Dixon, and Prescott, 1973; Walker et al, 1974) had revealed considerable variation in the extent of necrosis in different parts of the liver, a finding possibly related to the irregular lobar distribution of microsomal enzymes (Lawson and Pound, 1974). In order to minimize sampling errors multiple blocks have been examined in this study. It is evident from our finding of wide variation that unless it has been conclusively established that a lesion is diffusely and regularly distributed throughout the liver, estimation of its extent based on one or two blocks or on a needle biopsy sample must be viewed with circumspection.

The wedge-shaped areas of confluent necrosis found in rats given paracetamol in high dosage have been termed 'infarcts' by Gazzard, Hughes, Portmann, Dordoni, and Williams (1974) and were noted separately in their assessment of liver necrosis as they considered that such areas represented ischaemic damage. We feel that localized areas of confluent necrosis reflect the marked variation in the degree of toxic injury within the liver rather than resulting from secondary vascular effects, although it is possible that the extent of injury is exaggerated by congestion and hypoxia (Dixon, Dixon, and Aparicio, 1973). Whatever the precise pathogenesis of these confluent lesions, they are nevertheless part of the totality of liver injury and should therefore be included in any quantitation of liver necrosis. It is of interest that McLean and Day (1975) assessed the degree of paracetamol-induced necrosis by 'weighing the visibly affected portions on the basis of the very striking speckled white appearance' and expressing this as a percentage of the total liver weight. These portions probably correspond to the 'infarcts' of Gazzard et al (1974). Despite the arbitrary nature of the grading used in this study, repetition after an interval of several weeks indicated that the method is reproducible when used by an experienced observer.

A more accurate and objective method of histological quantitation is 'point counting' based on the method originally proposed by Chalkley (1943). Variations on this method have been applied to the quantitation of experimental carbon tetrachlorideinduced liver necrosis (Beck and Hughes, 1970; Adam and Thorpe, 1972) and to experimental paracetamol-induced necrosis (Mitchell, Jollow, Potter, Davis, Gillette, and Brodie, 1973; Walker et al, 1973). Point counting has also been used to estimate hepatocyte volume in liver biopsies from patients in acute hepatic failure (Scotto, Opolon, Étévé, Vergoz, Thomas, and Caroli, 1973), with the assumption that the biopsy forms a representative sample.

Although we found a very good correlation between the mean grade and the mean percentage necrosis as determined by point counting, the theoretical percentage necrosis equivalent to the mean grade consistently exceeded the corresponding point-count result. This overestimation is attributable to the allocation of grade 1 , equivalent to $20 \%$, to blocks in which there was any necrosis whatsoever, and to the natural tendency of an observer to exaggerate the extent of the 'sought' component.

The image analysis computer is a new approach to the measurement of liver necrosis. Whereas in theory the analysis of 500000 picture points per field would appear to offer a very accurate method of quantitation, in practice certain shortcomings detracted from its accuracy. Although the Pyronin Y stain in most cases enabled clear discrimination between viable and necrotic hepatocytes, when the viable cells had a high glycogen content the intensity of staining was reduced to a level that made distinction in the video image very difficult. Several staining techniques were tried, usually based on staining the necrotic areas with a variety of anionic dyes. None of these complex methods was found to be consistently superior to staining with Pyronin Y alone. Problems in discrimination led to overlap of the grey-level ranges of the different tissue components and the setting of the detection thresholds remained to some extent a subjective process. Improvements in the specificity and consistency of stains are therefore of great importance if the 
technique of image analysis is to gain in accuracy and usefulness.

Of the two quantitative methods more generally available, grading and point counting, the latter is more accurate but is very time-consuming and tedious. We feel that for experiments involving large numbers of animals where a relatively simple comparative assessment of necrosis is required, arbitrary grading of multiple samples is the most acceptable method.

Following paracetamol overdosage some patients have very striking rises in serum enzymes, levels which are rarely seen in any other form of liver disease. Despite these extreme elevations the patients may have little or no clinical evidence of liver disease. Though enzyme levels may be higher in those patients who develop fulminant hepatic failure, they may be of less help than other liver function tests in assessing eventual outcome (Clark et al, 1973), and the variability in response of serum enzymes in individual patients may make their prognostic value unreliable (Stewart and Simpson, 1973). Despite this, it is agreed by most authorities that serum ASAT is useful for detecting liver cell injury (Perez, Schaffner, and Popper, 1972; Sherlock, 1972). A detailed investigation of the usefulness of serum transaminase in predicting liver cell necrosis after paracetamol overdosage is not available.

The results of the present investigation suggest that the serum enzyme level gives a reliable indication of the severity of necrosis at that time, and this is true even in the recovery phase. The peak serum enzyme rise in rats after paracetamol usually occurs at about 24 hours, and is probably more predictable than the peak rise in patients which occurs later (Clark et al, 1973) and may be difficult to detect because of its very transient nature (Stewart and Simpson, 1973). Whilst measurement of the peak enzyme level gives a more accurate index of liver damage, levels obtained during the recovery phase are still closely related to the severity of the damage. It must be borne in mind, however, that for any given degree of histological necrosis the enzyme value at 72 hours is considerably lower than at 24 hours. The results of this study are in agreement with those of Balazs et al (1961), who, using a variety of hepatotoxins in the rat, found that serum enzyme levels at specified times following dosing generally reflected the severity of necrosis. Perhaps in the human situation if the time of paracetamol ingestion is known, the serum transaminase levels also reflect accurately the severity of liver damage but not nescesarily the prognosis in these patients.

We are grateful to Mr D. P. Loney for the excellent histological preparations, to Mrs D. Shillitoe and
Mrs D. Chippendale for expert technical assistance, to Mr T. Kenny for statistical advice, to Professor A. Williams of the Department of Fuel and Combustion Science for use of the Quantimet image analyser, and to the Sterling-Winthrop Group Ltd and the Yorkshire Cancer Research Campaign for financial support.

\section{References}

Adam, S. E. I., and Thorpe, E. (1972). Influence of cold environment on hepatic changes produced by repeated doses of carbon tetrachloride. J. Path., 106, 155-163.

Balazs, T., Murray, T. K., McLaughlan, J. M., and Grice, H. C. (1961). Hepatic tests in toxicity studies on rats. Toxicol. appl. Pharmacol., 3, 71-79.

Beck, J. S., and Hughes, P. (1970). In-vivo nuclear localisation of human antinuclear antibodies in mice with carbon tetrachloride and thioacetamide-induced hepatic necrosis. J. Path., 101, 11-26.

Block, W. D., and Cornish, H. H. (1958). Effect of carbon tetrachloride inhalation on rat serum enzymes. Proc. Soc. exp. Biol. (N.Y.), 97, 178-180.

Chalkley, H. W. (1943). Method for the quantitative morphologic analysis of tissues. $J$. nat. Cancer Inst., 4, 47-53.

Clark, R., Thompson, R. P. H., Borirakchanyavat, V., Widdop, B. Davidson, A. R., Goulding, R., and Williams, R. (1973) Hepatic damage and death from overdose of paracetamol. Lancet, 1, 66-69.

Curtis, A. S. C. (1960). Area and volume measurements by random sampling methods. Med. biol. Illust., 10, 261-266.

Cutler, M. G. (1974). The sensitivity of function tests in detecting liver damage in the rat. Toxicol. appl. Pharmacol., 28, 349-357.

Dixon, M. F., Dixon, B., and Aparicio, S. R. (1973). Treatment of acute paracetamol hepatotoxicity. Lancet, 2, 1387.

Dixon, M. F., Dixon, B., Aparicio, S. R., and Loney, D. P. (1975) Experimental paracetamol-induced hepatic necrosis: a lightand electron-microscope, and histochemical study. J. Path., 116, 17-29.

Fox, C. F., Dinman, B. D. and Frajola, W. J. (1962). $\mathrm{CCl}_{4}$ poisoning, II. Serum enzymes, free fatty acids and liver pathology. effects of phenoxybenzamine and phenergan. Proc. Soc. exp. Biol. (N.Y.), 111, 731-734.

Friend, C., Wroblewski, F., and La Due, J. S. (1955). Glutamicoxaloacetic transaminase activity of serum in mice with viral hepatitis. J. exp. Med., 102, 699-704.

Gabrieli, E. R., and Orfanos, A. (1968). Effect of carbon tetrachloride on serum glutamic-oxalacetic transaminase isoenzymes. Proc. Soc. exp. Biol. (N.Y.), 127, 766-770.

Gazzard, B. G., Hughes, R. D., Portmann, B., Dordoni, B., and Williams, R. (1974). Protection of rats against the hepatotoxic effect of paracetamol. Brit. J. exp. Path., 55, 601-605.

Grice, H. C., Barth, M. L., Cornish, H. H., Foster, G. V., and Gray, R. H. (1971). Correlation between serum enzymes, isozyme patterns and histologically detectable organ damage. Food Cosmet. Toxicol., 9, 847-855.

Henry, R. J., Chiamori, N., Golub, O. J., and Berkman, S. (1960). Revised spectrophotometric methods for the determination of glutamic-oxalacetic transaminase, glutamic-pyruvic transaminase and lactic acid dehydrogenase. Amer. J. clin. Path., 34, 381-398.

Karmen, A. (1955). A note on the spectrophotometric assay of glutamic-oxalacetic transaminase in human blood serum. J. clin. Invest., 34, 131-133.

Klaassen, C. D., and Plaa, G. L. (1967). Relative effects of various chlorinated hydrocarbons on liver and kidney function in dogs. Toxicol. appl. Pharmacol., 10, 119-131.

Lawson, T. A., and Pound, A. W. (1974). The different susceptibility of rat liver lobes to carbon tetrachloride and dimethylnitrosamine. Brit. J. exp. Path., 55, 583-588.

McLean, A. E. M., and Day, P. A. (1975). The effect of diet on the toxicity of paracetamol and the safety of paracetamolmethionine mixtures. Biochem. Pharmacol., 24, 37-42.

Magos, L., Butler, W. H., White, I. N. H., and Green, A. (1974). Pretreatment influences on SGPT levels and liver damage after 
inhalation of $\mathrm{CCl}_{4}$. Life Sci., 15, 1631-1637.

Mitchell, J. R., Jollow, D. J., Potter, W. Z., Davis, D. C., Gillette, J. R., and Brodie, B. B. (1973). Acetaminophen-induced hepatic necrosis. I. Role of drug metabolism. J. Pharmacol. exp. Ther., 187, 185-194.

Molander, D. W., Wroblewski, F., and LaDue, J. S. (1955). Serum glutamic oxalacetic transaminase as an index of hepatocellular integrity. J. Lab. clin. Med., 46, 831-839.

Nimmo, J., Dixon, M. F., and Prescott, L. F. (1973). Effects of mepyramine, promethazine and hydrocortisone on paracetamolinduced hepatic necrosis in the rat. Clin. Toxicol., 6, 75-81.

Perez, V., Schaffner, F., and Popper, H. (1972). Hepatic drug reactions. Progr. Liver Dis, 4, 597-625.

Prescott, L. F., Wright, N., Roscoe, P., and Brown, S. S. (1971). Plasma-paracetamol half-life and hepatic necrosis in patients with paracetamol overdosage. Lancet, 1, 519-522.

Richarz, G., and Schoetensack, W. (1959). Transaminasen in Blutserum der Ratte bei akuten und chronischen Leberschadigungen. Arch exp. Path. Pharmak., 236, 64-66.

Scotto, J., Opolon, P., tévé, J., Vergoz, D., Thomas, M., and Caroli, J. (1973). Liver biopsy and prognosis in acute liver failure Gut, 14, 927-933.

Sherlock, S. (1972). Clinical techniques for the elevation of therapeutic agents on the liver. In Liver and Drugs, edited by F. Orlandi and A. M. Jezequel, p. 193. Academic Press, New York.

Stewart, M. J., and Simpson. E. (1973). Prognosis in paracetamol self-poisoning: the use of plasma paracetamol concentration in a region without a poisoning treatment centre. Ann. clin. Biochem., 10, 173-178.

Strubelt, O., Breining, H., and Praël, H. (1973). Der diagnostische Aussagewert von Serumenzymen bei toxikologischen untersuchungen an Ratten. Arzneimittel-Forsch., 23, 77-82.

Walker, B. E., Kelleher, J., Dixon, M. F., and Losowsky, M. S. (1973). The effect of phenobarbitone pretreatment on paracetamol toxicity. Biomedicine, 19, 465-468.

Walker, B. E., Kelleher, J., Dixon, M. F., and Losowsky, M. S. (1974). Vitamin E protection of the liver from paracetamol in the rat. Clin. Sci., 47, 449-459.

Wirtschafter, Z. T., and Tsujimura, J. K. (1961). Serum glutamic oxaloacetic transaminase: specificity of values in hepatocellular injury. Arch. environ. Hlth, 2, 16-22.

Wroblewski, F., and LaDue, J. S. (1956). Serum glutamic pyruvic transaminase in cardiac and hepatic disease. Proc. Soc. exp. Biol. (N.Y.), 91, 569-571.

Zelman, S., Wang, C. C., and Appelhanz, I. (1959). Transaminases in serum and liver correlated with liver cell necrosis in needle aspiration biopsies. Amer. J. med. Sci., 237, 323-334. 